\title{
Research on Quality Monitoring System of Practical Teaching for Middle Vocational Undergraduate
}

\author{
Haitao Sun \\ College of Finance and Trade, Bohai University, Jinzhou, 121013, China \\ 65145170@qq.com
}

Keywords: middle vocational undergraduate; practical teaching; quality monitoring system

\begin{abstract}
Teaching quality is the lifeline for school survival and development. The establishment of scientific teaching quality monitoring system is an important part of education reform. The study is conducted for the characteristics of expand vocational undergraduate education and the problems in practice teaching. The study includes three aspects, one is practical teaching knowledge, content, functions, features, methods and objectives were studied; the second is the principles of practical teaching quality monitoring system, including directivity, science, feasibility, openness and cooperative; the third is the construction of quality monitoring system of practical teaching for middle vocational undergraduate, using graphics to show the monitoring system structure constituted by three levels, three blocks and three platforms. Results of this research will help strengthen teaching management and improve teaching quality.
\end{abstract}

\section{Introduction}

Practical teaching is the effective way to consolidate theoretical knowledge and deepen the understanding of theoretical knowledge, an important part to develop high-quality engineering and technical personnel who are innovative, an important platform to link theory and practice, cultivate students to master scientific methods and improve handling ability, which is beneficial to improve students' literacy and develop values [1]. "Several Opinions on Further Strengthening Education work in College of the Ministry of Education and other Departments" noted [2], strengthen education work in college is the necessary requirement to fully implement the Party's education policy, put the socialist core value system throughout the whole process of national education, in-depth implement quality education and vigorously improve the quality of education. Insist on the combination of education and productive labor and social practice is an important part of the Party's education policy. Insist on theory learning and the unification of innovative thinking and social practice, insist on learning from the practice and the masses, are the only way for college students' growth.

With the popularization of higher education, the scale of colleges and universities achieved leapfrog development. Teaching is the central task of the school, teaching quality is the lifeline for survival and development of the school, a reflection of the overall strength of the school. Establish scientific teaching quality monitoring system is conducive to strengthen teaching management and improve teaching quality; it is good for teachers to change their teaching concepts and constantly improve their overall quality. Promote scientization and standardization of teaching management, and effectively improve teaching management level and teaching quality to guarantee the realization of highly skilled personnel training goals in colleges. Middle vocational undergraduate belongs to undergraduate education, but it also has the characteristics of vocational education. In order to implement the strategy relying on science and education, middle vocational undergraduate education must focus on improving quality. Modern educational concepts as guide, system construction as fundament, effective information from continuous feedback as basis, we should build scientific, rational and effective quality monitoring system of practical teaching to ensure long-lasting increase in middle vocational undergraduate quality. 


\section{Related Knowledge of Practical Teaching for Middle Vocational Undergraduate}

According to the requirements of practice teaching, combined with the characteristics of students in middle vocational undergraduate, practical teaching for middle vocational undergraduate needs to know related knowledge, such as "Connotation, Function, Characteristic, Method, Target" and others, it is shown in Fig. 1.

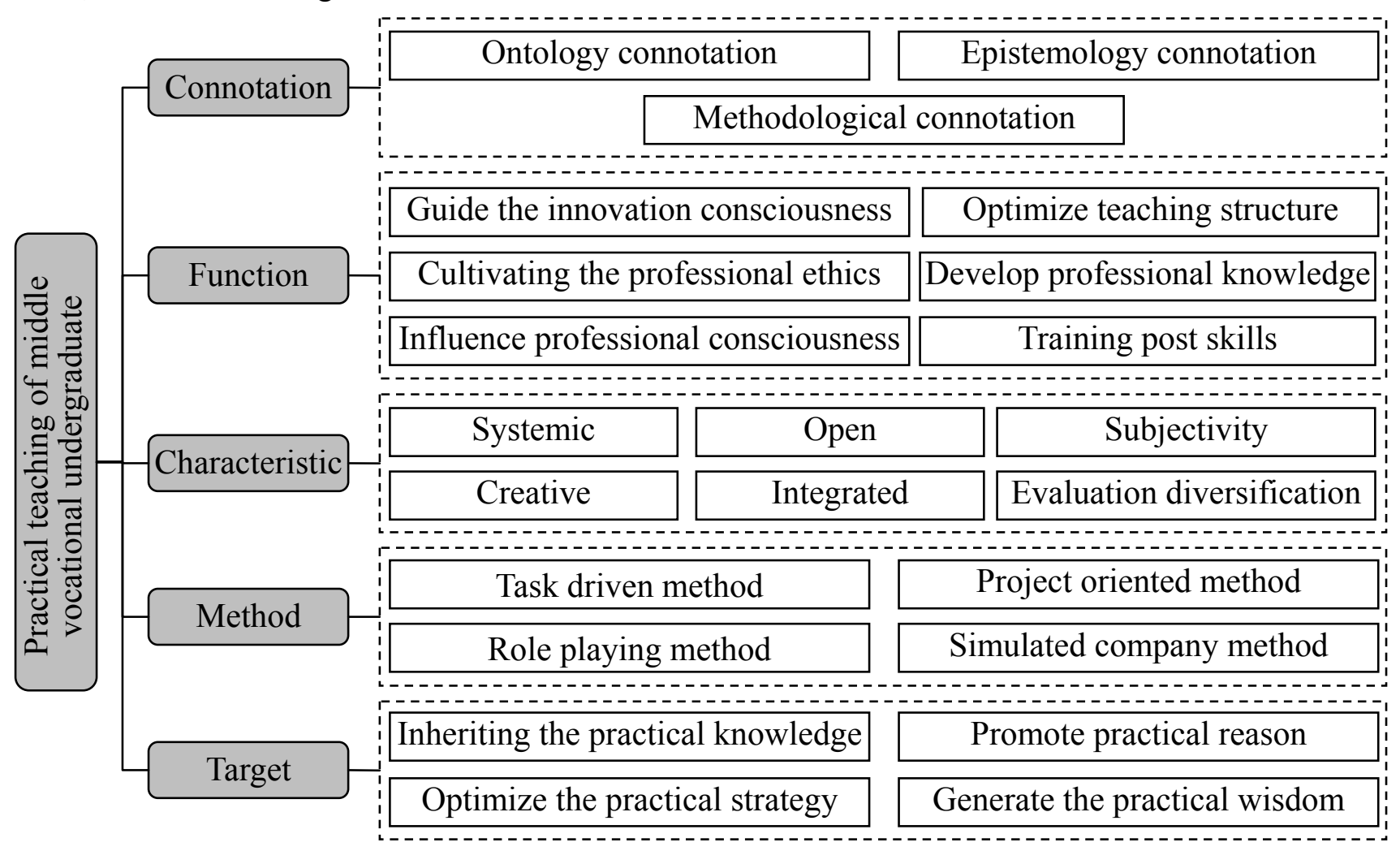

Fig. 1. Related knowledge on practical teaching of middle vocational undergraduate

(1) Connotation [2]. Connotation is an abstract sense, cognition for things, content hidden in the depths of things, which needs to be explored, excavated before we can see. Practical teaching for middle vocational undergraduate has three connotations: Ontology connotation, interactive activities between students and teachers as the ontology of practical teaching research object; Epistemology connotation, the practice has higher universality than the theoretical understanding, which provides theory basis and practice standards for practical teaching, practical teaching not only accept and master knowledge, but also to realize the inherent requirements of educating people. Methodological connotation provide a scientific way of thinking for teachers and students, starting from the practice point of view, they can form a way of practice thinking with new characteristics based on digesting and absorbing the rationality of pure objectivity and subjectivity thinking.

(2) Function $[4,5]$. Practical teaching for middle vocational undergraduate has six functions: Develop professional knowledge, practical teaching not only improves students' professional interests and enhances professional awareness, but also to broaden their horizons and knowledge; Optimize teaching structure, through practical teaching, qualitative change in the teaching structure conforms with characteristics and laws of middle vocational undergraduate education; Cultivating the professional ethics, students went to the site environment that can help students understand the occupational characteristics and compliance with professional standards, so that they can develop good professional and moral qualities; Guide the innovation consciousness, question-driven approach can inspire students thinking, guide students to discover laws and foster students to think positively to trigger innovation awareness; Training post skills, training students ability to solve practical problems in practical activities, so that they can form a variety of professional ability; Influence professional consciousness, professional awareness is awareness, understanding, attitude 
and positioning for career, students can experience and feel real workplace by means of practical teaching.

(3) Characteristic [6,7]. Based on different disciplines, practical teaching has different curriculum, teaching objectives and evaluation methods, but all of them have six common characteristics: Systemic, attach importance to train general and professional operation capabilities; Open, practical teaching not only open to profession, but also peer; Subjectivity, emphasize student-centered, focus on skills training, they can do things by themselves; Creative, practical teaching not only focus on skills training, but also focus on developing students' creativity; Integrated, sort out and integrate all aspects of education to form a unified framework and achieve the purpose of coordination play; Evaluation diversification, both schools and enterprises participate practical teaching, so the teaching evaluation for practical teaching has diversity, first is paying attention to the process of evaluation, second is that the evaluation forms is variety, third is that evaluate subject is diversity.

(4) Method [8]. Practical teaching complies with understanding law, and the learned theoretical knowledge can be tested by practice, which focuses on all aspects of student development. Practical teaching has a variety of methods that can be summarized into four suited for middle vocational undergraduate: Task driven method provides students with practical experience situation and an understanding of the problem situation, which around the mission to start learning; Project oriented method is a practice-premised, teacher-led, student-centered, project as media and professional competence-targeted teaching method. Students can master professional knowledge and operating skills when they involved in the project; Role playing method can improve students' initiative based on interactive teaching, and its teaching process is life and art; Simulated company method can help students to experience real companies in simulation companies, acquired knowledge and skills by them are likely to migrate to the real work scenario.

(5) Target. The goal of practical teaching is the fundamental basis for colleges building practicality talents' training model, which is at the heart of the theory and practice of practical teaching in universities. A sense of purpose must be had to carry on practical teaching. Inheriting practical knowledge, improving practical rationality, optimizing practical strategies and generating practical wisdom is an organic whole. Practical knowledge is the basis for solving the problem of how to do; practical rationality is the kernel for solving the problem of direction; practical strategies is the intermediary of practical knowledge into practical wisdom for solving the problem of how to do better, which is constrained by practical rationality; practical wisdom plays a co-ordination role in how to solve problems creatively while facing complex and new things.

\section{Construction Principle on Quality Monitoring System of Practical Teaching for Middle Vocational Undergraduate}

Construction on quality monitoring system of practical teaching for middle vocational undergraduate should follow the following principles:

(1) Directivity principle. The primary problem for constructing quality monitoring system of practical teaching is to know your goal. Firstly, standardize behaviors of practical teaching, strengthen management of practical teaching, strengthen logistics support services; secondly, to ensure continuous improvement of the quality of practical teaching by incentives; and thirdly, play the initiative of students and teachers so that they can burst out learning motivation.

(2) Scientific principle. Quality monitoring of practical teaching can not serve as an executive order, you must apply scientific theories and methods to study the relationship between the elements in internal system, and use the method combined by qualitative and quantitative evaluation to develop specific indicators of monitoring and evaluation, making precise quantification and fuzzy quantification complementary, and using multi-channel to monitor and evaluate.

(3) Feasibility principle. Feasibility is the fundamental guarantee to promote quality monitoring system of practical teaching effectively and make it success, the concrete performance is in four, the first is time feasibility, it can operate efficiently; the second is financial feasibility, it must can save resources and inputs; the third is operational feasibility, it can ensure clear control standards; the 
fourth is evaluation feasibility, making the system easy to promote and implement based on objective and comprehensive.

(4) Openness principle. Practical teaching is an open system, which needs remain open to the same industry, business and society, it must be industry and society demand-driven and introduce advanced technologies and processes outcomes fast, practical content and job demand achieve "zero distance" connection, teaching sites, teaching process and teachers configured and others are linked to business and industry.

(5) Cooperative principle. Industry cooperation is the only way of educational development. Construction on practical teaching system must be fully guaranteed that combine curricular and extracurricular, combine inside school and outside school and integrate content of practical teaching to achieve students' knowledge, ability, quality coordinated development, so that "win-win" cooperation mechanism can be achieve.

\section{Construction on Quality Monitoring System of Practical Teaching for Middle Vocational Undergraduate}

Quality monitoring system of practical teaching for middle vocational undergraduate is constituted by the "Three levels, Three modules, Three platforms", which is shown in Fig. 2 [9].

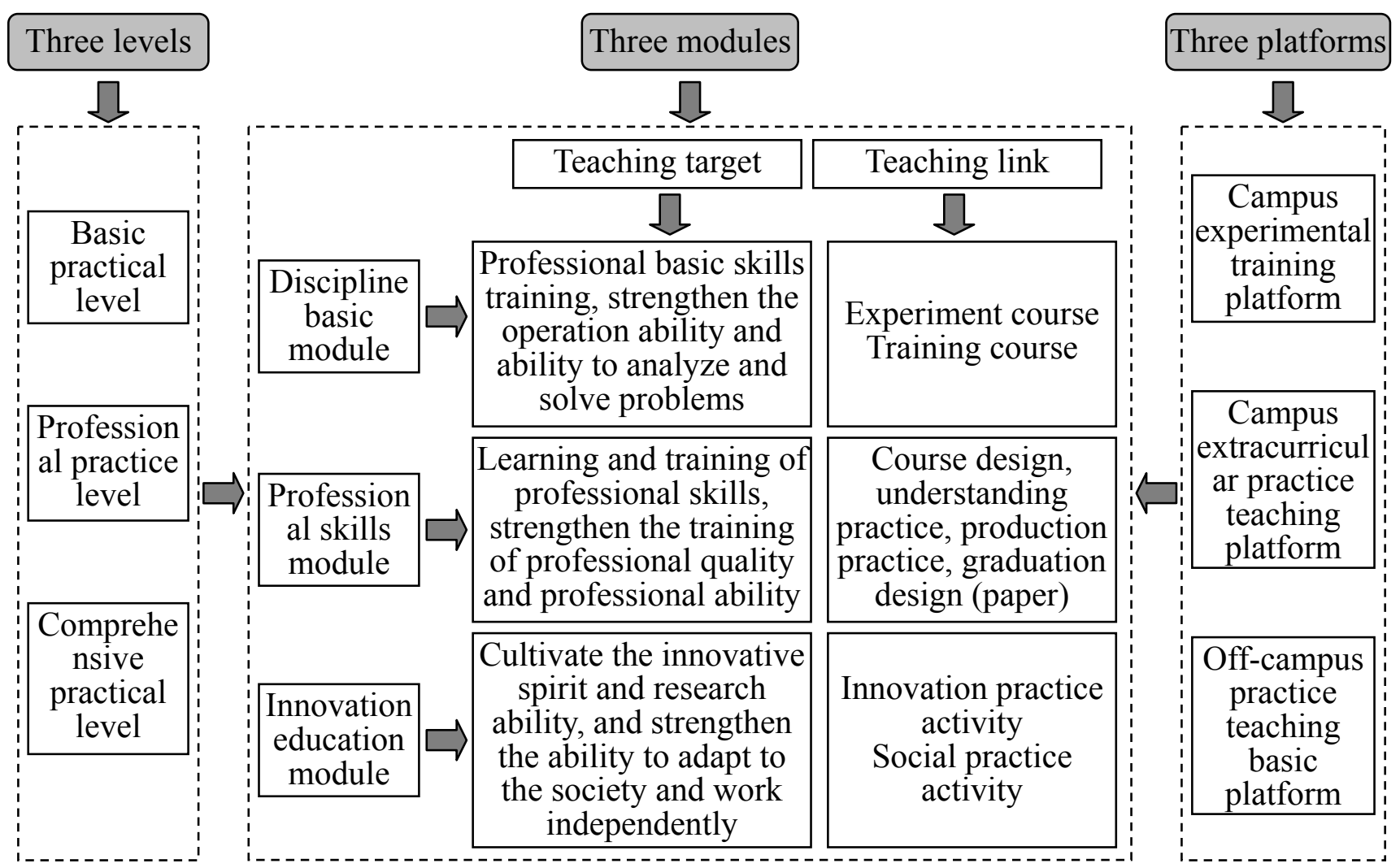

Fig. 2. Quality monitoring system of practical teaching for middle vocational undergraduate

"Three levels" are "Basic practical level, Professional practice level and Comprehensive practical level". Wherein, the purpose of "Basic practical level" is to train students' basic abilities. Basic abilities include basic knowledge, basic skills, learning ability and science and humanities when students adapt to social life. A solid cultural knowledge can be trained through basic practice level, including professional and non-professional knowledge, eventually forming their own knowledge system; the purpose of "Professional practice level" is to develop the students' ability in the professional aspects. The actual classroom teaching not really achieve mastery of knowledge, students have learned is simple pile many courses, learned professional knowledge can be used into practice effectively to enhance students' exertion ability by professional practice level, so that students meet the needs of the community while continuing to enhance the competitiveness; the 
purpose of "Comprehensive practical level" is to train the students ability to use knowledge. Comprehensive practical activities provide a relatively independent learning space, students are the leader in this space, and students have absolute control over the whole event and ownership. Students seek to complete activities independently, rather than listen to the teachings and instructions. Teachers are only guides, mentors and bystanders in comprehensive practical activities.

"Three modules" are "Discipline basic module, Professional skills module and Innovation education module". Wherein, "Discipline basic module", the basic courses are organized by categories, so that students have a wide professional basis. Individual basic courses will be set for these can not form subject group; "Professional skills module", the setting of professional core courses needs to reflect the requirements of professional training objectives, and profession' characteristics and school characteristics, which trains students that have professional knowledge and scientific thinking when they engage in the professional work; "Innovation education module" is to cultivate the innovation spirit and innovation ability. The fundamental purpose of education innovation is to promote quality education and improve the quality of education. Reform the teaching content, methods and means, improve talent training mode, fully absorb the latest achievements of modern natural science and the humanities and social sciences, establish a new teaching model that can stimulate students' creativity and in line with the law of overall development of students, form mutual encouraged and mutual promoted the teacher-student relationship, efforts to create a good education and social environment conditions conducive to the growth of innovative talents, so that every educated can give full play to their potential, their initiative of learning and growth will be stimulated to achieve comprehensive development.

"Three platforms" are "Campus experimental training platform, Campus extracurricular practice teaching platform and Off-campus practice teaching basic platform". Wherein, "Campus experimental training platform", is the place in school to implement practical training, which achieves training teaching, professional quality training and professional skills training and identification, and it will gradually develop into an important base of practical teaching, professional skills training and identification and high-tech applications for training higher vocational education personnel; "Campus extracurricular practice teaching platform", practical teaching platform of middle vocational undergraduate must possess "professional environment" consistent with the production, construction, management, service and others. Technology ability training and professional quality training can be carried out in a highly simulation professional environment, so that students mastered knowledge and skills closely integrate with the market demand, after the students graduate, they can directly into the enterprises and rapid post; "Off -campus practice teaching basic platform", practical training base construction in school is often insufficient funding and space, the practical training base outside the school can make up deficiencies in equipment, space and functionality, students and professional technology post can achieve "zero distance", consolidate theoretical knowledge, train professional skills, shorten working adaptation period, improve the overall quality of students.

\section{Conclusion}

Increase the breadth and depth of practical teaching research in universities, make clear objective system of practical teaching, have great significance in deepening practical teaching reform, deepening the understanding of practical teaching law, enhancing the consciousness of carrying out practical teaching, protecting the effect of practical teaching and improving the quality of practical teaching. Middle vocational undergraduate is a new higher education way emerged in recent years, which achieved dream for vocational students entering colleges. Results of this study have irreplaceable important role to further strengthen the practical education work of universities, constantly enhance social responsibility that students service for the national and people, the spirit of innovation of courage to explore, good practical ability to solve problems. 


\section{Acknowledgement}

This work is supported by 2014 annual teaching reform project in Bohai university (BDJZ-14-ZZ-C-003): Research on Quality Monitoring System of Practical Teaching for Middle Vocational Undergraduate.

\section{References}

[1] Baidu Encyclopedia, "Practical teaching," http://baike.baidu.com/link?url=P4MJCoLnLcDTvFeMWimlaOQ6IpVu876PazOJMuiL9Bfc31 Flf0xHnFvmuKMauemmpk-9vZhJrymjnvai1 oiUSa, 2015-10-20.

[2] Ministry of education of the people's Republic of China, " Some opinions on Further Strengthening the practice of the Education Department of the Ministry of education and other departments,"

http://www.moe.gov.cn/publicfiles/business/htmlfiles/moe/s6870/201209/142870.html, 2015-10-20.

[3] Y. Yang, S. H. Lou, "University teaching practices: connotations, characteristics and trends," Journal of Hebei Normal University (Educational Science Edition), vol. 16, no. 1, pp. 113-118, 2014.

[4] X. Y. Gao, "Study on practical teaching in colleges and universities based on the perspective of professional quality," Adult Education, vol. 33, no. 11, pp. 32-33, 2013.

[5] P. A. Wang, "Effect on the practical teaching of vocational education," Chinese Vocational and Technical Education, vol. 17, no. 9, pp. 13-15, 2009.

[6] H. Guo, "The stage and characteristics of the development of higher vocational education practice teaching system in China," China Adult Education, vol. 24, no. 2, pp. 88-89, 2014.

[7] Zoomlion Paper network, "Effect on Practice teaching in Vocational Education," http://www.zllunwen.com/jiaoyulw/37707.html, 2015-10-20.

[8] Y. Zhang, "A Review on Context Theory," Master's degree of Hunan Agricultural University, 2012.

[9] Baidu Picture, "Diversified practice teaching content system," http://image.baidu.com/search/index?tn=baiduimage \&ipn=r\&ct $=201326592 \& \mathrm{cl}=2 \& \mathrm{~lm}=-1 \& \mathrm{st}=$ $-1 \& \mathrm{fm}=\mathrm{ala} \& \mathrm{fr}=\mathrm{ala} \& \mathrm{sf}=1 \& \mathrm{fmq}=1446120510216 \_\mathrm{R} \& \mathrm{pv}=\& \mathrm{ic}=0 \& \mathrm{nc}=1 \& \mathrm{z}=\& \mathrm{se}=\& \mathrm{showtab}=0 \&$ $\mathrm{fb}=0 \&$ width $=\&$ height $=\&$ face $=0 \&$ istype $=2 \& i \mathrm{e}=$ utf- $8 \&$ word $=$ Practical teaching system + Figure , 2015-10-20. 